\title{
Techniques used to identify the Brazilian variant of HIV-1 subtype B
}

\footnotetext{
S. Komninakis ${ }^{1}$, L. Fukumori ${ }^{1}$, R. Alcalde ${ }^{1}$, M. Cortina ${ }^{1}$, L. Abdala ${ }^{1}$, A. Brito ${ }^{1}$,

S. Sanabani ${ }^{3}$, A.J.S. Duarte ${ }^{1}$ and J. Casseb ${ }^{1,2}$
}

\author{
${ }^{1}$ Laboratório de Alergia e Imunologia Clínica e Experimental, LIM-56, \\ Departamento de Dermatologia, Faculdade de Medicina, \\ Universidade de São Paulo, São Paulo, SP, Brasil \\ 2Instituto de Infectologia "Emílio Ribas", São Paulo, SP, Brasil \\ ${ }^{3}$ Fundação Pró-Sangue, Hemocentro de São Paulo, São Paulo, SP, Brasil
}

\author{
Correspondence \\ J. Casseb \\ Laboratório de Alergia e Imunologia \\ Clínica e Experimental - LIM-56 \\ Departamento de Dermatologia \\ Faculdade de Medicina, USP \\ Av. Dr. Enéas C. Aguiar, 500 \\ Prédio II, $3^{\circ}$ andar, \\ 05403-000 São Paulo, SP \\ Brasil \\ Fax: +55-11-3081-7190 \\ E-mail: shirley_200@hotmail.com \\ S. Komninakis is a post-doctoral \\ fellow in the Laboratório de \\ Retrovirologia, Universidade \\ Federal de São Paulo, São Paulo, \\ SP, Brasil. \\ Research supported by FAPESP \\ (Nos. 97/11502-2, 00/12367-9, \\ 00/11868-1).
}

Received May 12, 2006

Accepted November 24, 2006

\begin{abstract}
The purpose of the present study was to compare the sensitivity and specificity of V3 enzyme immunoassay (solid phase EIA and EIA inhibition) and restriction fragment length polymorphism (RFLP) with the DNA sequencing "gold standard" to identify the Brazilian HIV-1 variants of subtype B and B"-GWGR. Peripheral blood mononuclear cells were collected from $61 \mathrm{HIV}-1$-infected individuals attending a clinic in São Paulo. Proviral DNA was amplified and sequentially cleaved with the Fok I restriction enzyme. Plasma samples were submitted to a V3-loop biotinylated synthetic peptide EIA. Direct partial DNA sequencing of the env gene was performed on all samples. Based on EIA results, the sensitivity for detecting B-GPGR was $70 \%$, compared to $64 \%$ for the Brazilian variant B"-GWGR while, the specificity of B-GPGR detection was $85 \%$, compared to $88 \%$ for GWGR. The assessment of RFLP revealed $68 \%$ sensitivity and $94 \%$ specificity for the B-GPGR strain compared to 84 and $90 \%$ for the B"-GWGR variant. Moreover, direct DNA sequencing was able to detect different base sequences corresponding to amino acid sequences at the tip of the V3 loop in 22 patients. These results show a similar performance of V3 serology and RLFP in identifying the Brazilian variant GWGR. However, V3 peptide serology may give indeterminate results. Therefore, we suggest that V3 serology be used instead of DNA sequencing where resources are limited. Samples giving indeterminate results by V3 peptide serology should be analyzed by direct DNA sequencing to distinguish between B-GPGR and the Brazilian variant B"-GWGR.
\end{abstract}

The current Brazilian HIV/AIDS epidemic is mainly caused by subtype B; however, the existence of a small proportion of other subtypes such as F, C, B/C, and B/F has been consistently described $(1,2)$. Several studies have reported the existence of a Bra-
Key words

- HIV-1 subtyping

- Brazilian subtype B variant

- Serotyping

- DNA sequencing zilian subtype B variant designated as subtype B" (3-10). This variant has a characteristic tetramer (GWGR) amino acid sequence coded by the tip of the V3 loop, distinct from variants that have other V3 loop tetramers such as GPGR which are found in the USA 
and Europe. The difference between the BGPGR and B"-GWGR isolates is limited to the proline, the amino acid coded by the CCA codon, found in the B-GPGR strains and the tryptophan, coded by the TGG codon, found in the Brazilian variants B"-GWGR (5). The two variants can be distinguished using genetic and antigenic approaches (7, 11,12 ), although consistent cross-neutralization has been observed. DNA sequencing is a powerful technique to distinguish the two variants. However, due to its expense, DNA sequencing is often used only in the research laboratories. The purpose of the present study was to determine whether V3 serology and restriction fragment length polymorphism (RFLP) assay can be used to identify the Brazilian variant B"-GWGR, as well as direct DNA sequencing.

A total of 61 blood samples were collected into EDTA from HIV-1-infected subjects from São Paulo, SP, Brazil. The average age of the patients was 35 years. Twentyone percent of the subjects were females. A

Figure 1. RFLP detection of the env proviral DNA products from 3 representative patients. Lanes 1 and 2 show 540- and 340-bp bands and correspond to the Brazilian subtype B"-GWGR. Lanes 2 and 4 show different band pattern for samples classified as indeterminate. Lanes 5 and 6 show undigested bands and correspond to the Brazilian subtype B-GPGR. The M lane is a molecular weight marker.
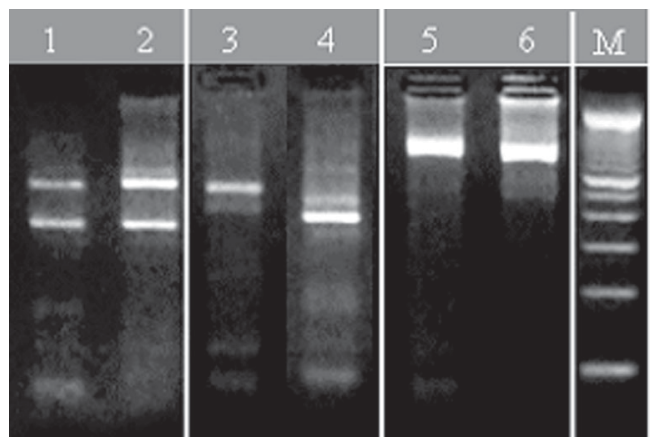

Table 1. Comparison of enzyme immunoassay, RFLP, and direct DNA sequencing for the detection of the subtype B motif.

\begin{tabular}{lccc}
\hline Subtype B motif & V3 serology & RFLP & DNA sequencing \\
\hline B-GPGR & $33(54.1 \%)$ & $28(45.9 \%)$ & $20(32.8 \%)$ \\
B"-GWGR & $28(45.9 \%)$ & $16(26.2 \%)$ & $19(31.1 \%)$ \\
Different amino acids at the V3 loop & - & - & $22(36.1 \%)$ \\
Indeterminate & - & $17(27.9 \%)$ & -
\end{tabular}

Data are reported as number of patients with percent in parentheses. RFLP = restriction fragment length polymorphism. detailed description of this cohort has been reported elsewhere $(13,14)$. We used a previously described set of biotinylated synthetic peptides based on the V 3 loop consensus sequence from two subtype $B$ strains (MN: N K R K R I H I G P G R A F Y, SF2: N T R K S I Y I G P G R A F Y) and two synthetic peptides based on the consensus sequence of two Brazilian variant subtype $B$ strains (BR1: N T R K S I H I G W G R A F Y, BR2: N T R K S I H M G W G R A F Y) in enzyme immunoassay (EIA; 6,15). For RFLP and DNA sequencing, proviral DNA was extracted from peripheral blood mononucler cells using the genomic blood DNA purification kit of Amersham Pharmacia Biotech, Inc. (Piscataway, NJ, USA) according to manufacturer instructions. The extracted DNA was used as a template to partially amplify the env gene in a nested PCR fashion using the primer sets ED5/ ED12 (outer) and ED31/ES8 (inner; http:// www.nih.gov). The Fok I restriction enzyme was used in the RFLP reaction to cleave the sequence GGA TGG (Pro Trp) that characterizes the Brazilian variant B"-GWGR. Samples were defined as positive for the Brazilian subtype B-GWGR by RFLP if their amplified products cleaved into 2 fragments of approximately 540 and $340 \mathrm{bp}$, respectively (Figure 1). Samples that showed different band pattern were considered to be indeterminate. For direct DNA sequencing, both partial env complementary strands were directly sequenced with internal primers, fluorescent-dye terminators, and Taq polymerase with an automated sequencer (ABI 377; Applied Biosystems, Inc., Foster City, CA, USA). A consensus sequence of both strands was constructed with the Sequencher program (Gene Code Corp., Ann Arbor, MI, USA).

Analysis of the tetramer amino acid sequences at the tip of the V3 loop of all samples revealed 20 GPGR, 19 GWGR, and 22 with different amino acids (Table 1). Thirty-three $(54.1 \%)$ plasma samples were 
positive for the B-GPGR variant and 28 $(45.9 \%)$ were positive for the B"-GWGR variant by both the EIA solid phase and EIA inhibition tests. EIA showed $70 \%$ sensitivity for the detection of B-GPGR compared to $64 \%$ for the Brazilian variant B"-GWGR, and $85 \%$ specificity for the detection of BGPGR compared to $88 \%$ for GWGR. The assessment on the basis of RFLP results, excluding samples with an indeterminate band pattern, showed $68 \%$ sensitivity and 94\% specificity for the B-GPGR strain compared to 84 and $90 \%$, respectively, for the B"-GWGR variant. The band pattern obtained by RFLP was indeterminate in 17 (27.9\%) samples. Because the Fok I restriction enzyme recognizes and cleaves GGA (corresponding to glycine) and TGG (tryptophan) sequences, the frequency of the cleavage site considered was investigated in 19 B"-GWGR samples. The GGA codon was observed in 18 of the 19 samples. Of these, 6 samples gave an indeterminate band pattern by RFLP and 12 were cleaved by the Fok I enzyme. One sample was not cleaved because it contained a single base mismatch at the 3rd position of the glycine codon.

$\mathrm{V} 3$ peptide serology is an easy technique and can be useful particularly in developing countries, where resources are limited. In addition, the peptides have amino acid sequences and conformations that may minimize the differences in V3 loop conformation between subtypes $(16,17)$.

Serum reactivity to the Brazilian B"GWGR variant is highly specific, probably due to the conformation of tryptophan in the V3 loop. One explanation is that the betaturn structure at the V3 loop of GPGR is lost in the GWGR motif (18). In fact, testing for avidity antibodies against the V3 loop showed a higher avidity index in B"-GWGR patients and also a lower number of AIDS clinical events among these patients $(9,19,20)$.

Despite the high specificity and sensitivity of V3 serology, one third of the samples were indeterminant and therefore would not have been accurately identified if only serology had been used in the present study. Since some of these patients have been under combined retroviral therapy for nine years (data not shown), it is possible that the viral sequences experienced strong positive selection that resulted in a conformational change of the V3 loop structure and thus affected antibody recognition.

Although the sample size was small, the V3 EIA presented high specific reactivity and a fair positive predictive value with samples from patients with the B'-GWGR variants. Therefore, this method appears to be reliable for identifying the HIV-1 subtype $B$ in Brazil as B"-GWGR or non-GWGR. However, when indeterminant samples are detected, direct DNA sequencing must be used.

\section{Acknowledgments}

We thank Dana Gallo for a critical review and for helpful comments on the manuscript.

\section{References}

1. Morgado MG, Sabino EC, Shpaer EG, Bongertz V, Brigido L, Guimaraes MD, et al. V3 region polymorphisms in HIV-1 from Brazil: prevalence of subtype B strains divergent from North American/ European prototype and detection of subtype F. AIDS Res Hum Retroviruses 1994; 10: 569-576.

2. Couto-Fernandez JC, Janssens W, Heyndrickx L, Motte J, Fransen $\mathrm{K}$, Peeters M, et al. Genetic and antigenic variability of HIV type 1 in Brazil. AIDS Res Hum Retroviruses 1994; 10: 1157-1163.
3. Sabino EC, Diaz RS, Brigido LF, Learn GH, Mullins JI, Reingold AL, et al. Distribution of HIV-1 subtypes seen in an AIDS clinic in São Paulo city, Brazil. AIDS 1996; 10: 1579-1584.

4. Potts KE, Kalish ML, Lott T, Orloff G, Luo CC, Bernard MA, et al. Genetic heterogeneity of the V3 region of the HIV-1 envelope glycoprotein in Brazil. Brazilian Collaborative AIDS Research Group. AIDS 1993; 7: 1191-1197.

5. da Costa SM, Schechter M, Shindo N, Vicente AC, Oliveira EF, 
Pinto ME, et al. Sequence and phylogenetic analysis of glycoprotein 120 of an HIV type 1 variant (GWGR) prevalent in Brazil. AIDS Res Hum Retroviruses 1995; 11: 1143-1145.

6. Hendry RM, Hanson CV, Bongertz V, Morgado M, Duarte A, Casseb $\mathrm{J}$, et al. Immunoreactivity of Brazilian HIV isolates with different V3 motifs. Mem Inst Oswaldo Cruz 1996; 91: 347-348.

7. Covas DT, Biscaro TA, Kashima S, Duarte G, Machado AA. High frequency of the GWG (Pro Trp) envelope variant of HIV-1 in Southeast Brazil. J Acquir Immune Defic Syndr Hum Retrovirol 1998; 19: 74-79.

8. Brito A, Komninakis SCV, Novoa P, de Oliveira RM, Fonseca LA, Duarte $A J$, et al. Women infected with HIV type 1 Brazilian variant, subtype B (B"-GWGR motif) have slower progression to AIDS, compared with patients infected with subtype B (B-GPGR motif). Clin Infect Dis 2006; 43: 1476-1481.

9. Casseb J, Komninakis S, Abdalla L, Brigido LF, Rodrigues R, Araujo F, et al. HIV disease progression: is the Brazilian variant subtype B' (GWGR motif) less pathogenic than US/European subtype B (GPGR)? Int J Infect Dis 2002; 6: 164-169.

10. Casseb J, Hong MA, Gonsalez C, Brigido LF, Duarte AJ, MichaelHendry R. Two variants of HIV-1 B serotype are transmitted heterosexually in São Paulo, Brazil. Braz J Med Biol Res 1998; 31: 12431246.

11. Bello G, Guimaraes ML, Morgado MG. Evolutionary history of HIV-1 subtype $\mathrm{B}$ and $\mathrm{F}$ infections in Brazil. AIDS 2006; 20: 763-768.

12. Murphy G, Belda FJ, Pau CP, Clewley JP, Parry JV. Discrimination of subtype $B$ and non-subtype $B$ strains of human immunodeficiency virus type 1 by serotyping: correlation with genotyping. J Clin Microbiol 1999; 37: 1356-1360.

13. Fonseca LA, Reingold AL, Casseb JR, Brigido LF, Duarte AJ. AIDS incidence and survival in a hospital-based cohort of asymptomatic HIV seropositive patients in São Paulo, Brazil. Int J Epidemiol 1999;
28: $1156-1160$

14. Casseb J, Fonseca LA, Veiga AP, de Almeida A, Bueno A, Ferez $A C$, et al. AIDS incidence and mortality in a hospital-based cohort of HIV-1-seropositive patients receiving highly active antiretroviral therapy in São Paulo, Brazil. AIDS Patient Care STDS 2003; 17: 447-452.

15. Sherefa K, Sonnerborg A, Steinbergs J, Sallberg M. Rapid grouping of HIV-1 infection in subtypes A to $E$ by V3 peptide serotyping and its relation to sequence analysis. Biochem Biophys Res Commun 1994; 205: 1658-1664.

16. Vasan A, Renjifo B, Hertzmark E, Chaplin B, Msamanga G, Essex $M$, et al. Different rates of disease progression of HIV type 1 infection in Tanzania based on infecting subtype. Clin Infect Dis 2006; 42: 843-852.

17. Barin F, Plantier JC, Brand D, Brunet S, Moreau A, Liandier B, et al. Human immunodeficiency virus serotyping on dried serum spots as a screening tool for the surveillance of the AIDS epidemic. $J$ Med Virol 2006; 78 (Suppl 1): S13-S18.

18. Rosen O, Chill J, Sharon M, Kessler N, Mester B, Zolla-Pazner S, et al. Induced fit in HIV-neutralizing antibody complexes: evidence for alternative conformations of the gp120 V3 loop and the molecular basis for broad neutralization. Biochemistry 2005; 44: 7250-7258.

19. Morgado MG, Guimaraes ML, Gripp CB, Neves Junior I, Costa Cl, dos Santos V, et al. Polymorphism of the predictive antigenic sites on the V3 loop of Brazilian HIV-1 subtype B strains. HEC/FIOCRUZ AIDS Clinical Research Group. Mem Inst Oswaldo Cruz 1996; 91: 339-342.

20. Santoro-Lopes G, Harrison LH, Tavares MD, Xexeo A, Dos Santos $A C$, Schechter M. HIV disease progression and V3 serotypes in Brazil: is B different from B-Br? AIDS Res Hum Retroviruses 2000; 16: 953-958. 